\title{
The structure of the breast in mucoviscidosis
}

\author{
A. MILFORD WARD
}

From the Department of Pathology, University of Sheffield

SYNOPSIS The histological appearances of the breast in a patient with mucoviscidosis are those of complete lobular agenesis. Ducts and ductules are well developed, and there is abundant fibrous tissue giving the breast a normal contour. The appearances are contrasted with those of gynaecomastia, and the aetiology is discussed.

Fibrocystic disease of the pancreas, or mucoviscidosis, is a congenital disorder of mucus production (Bodian, 1952) affecting all exocrine glands to a greater or lesser extent, although the degree of dysfunction is not always clinically apparent. It is not a rare disease, with an incidence of $1 \cdot 8$ /thousand live births (Stowens, 1966) but a high infant and child mortality makes the condition uncommon in the adult. With modern therapeutic measures, however, it is being seen in the adult with increasing frequency, Brusilow (1970) suggesting a figure 5\% of all cases for the proportion surviving past the age of 17 years.

Mucoviscidosis is primarily a generalized disease of exocrine secretory elements involving the destruction and hypofunction of the glandular parenchyma. Although the anatomical changes in the pancreas are the best documented, all glands of the alimentary canal and its accessory structures show some abnormality (di Sant Agnese, 1956). Abnormalities of bronchial mucus glands are also well documented, but other exocrine glands have received scant attention. Sweney and Warwick (1968) and Doggett, Bentinck, and Harrison (1971) have described changes in the labial salivary glands, but as yet there appears to be no description of anatomical changes in the lacrimal gland or dermal sebaceous glands.

The present case illustrates the anatomical changes that are seen in the breast.

\section{Case Report}

The patient was a woman aged 20 years, who had been under treatment for mucoviscidosis since the age of 4 years. Repeated respiratory infections had necessitated many admissions to hospital during the intervening 16 years. She developed bronchiectasis in the right upper lobe at the age of 6 years, and this Received for publication 22 July 1971. had been steadily progressive. At the age of 15 she began to have repeated sinus infections and the maxillary antra became radiologically opaque. At necropsy the body was that of a well developed and well nourished young adult female. Secondary sexual characteristics were normally developed and consistent with the stated age of 20 years. The breasts, however, were rather small and solid. Death was due to acute cor pulmonale with an exacerbation of chronic asthmatic bronchitis. There was severe panacinar emphysema and purulent bronchiectasis involving both lower lobes and the right upper lobe. The pancreas was represented by a fibrofatty cord containing only islet tissue grouped around dilated exocrine ducts. No exocrine acinar tissue was present. The liver, gallbladder, and intestines were macroscopically normal. The pituitary, thyroid, adrenals, and ovaries were normal. The uterus and fallopian tubes were of normal size and contour for the age. The breast discs measured $11 \times 12 \times 3 \mathrm{~cm}$ each and weighed $295 \mathrm{~g}$ (fixed weight). They were of a solid consistency, and the cut surface showed dense fibrous tissue without the usual nodular appearance. There were no grossly ectatic ducts. The nipples and areolae were normal.

\section{Histopathology}

Sections from the breast show abundant dense fibrous tissue with sparse ducts and ductules, and complete lobular agenesis. The main and subsidiary ducts are well developed (Figs. 1, 2, and 3). The ductules are quiescent, and show no evidence of budding. The lobules, where there is any evidence of development, show only a rudimentary pattern (Figs. 2 and 3) with a few solid islands of cells surrounded by dense hyaline masses of basement membrane material fused to intralobular connective tissue (Fig. 4). This material does not have the staining characteris- 


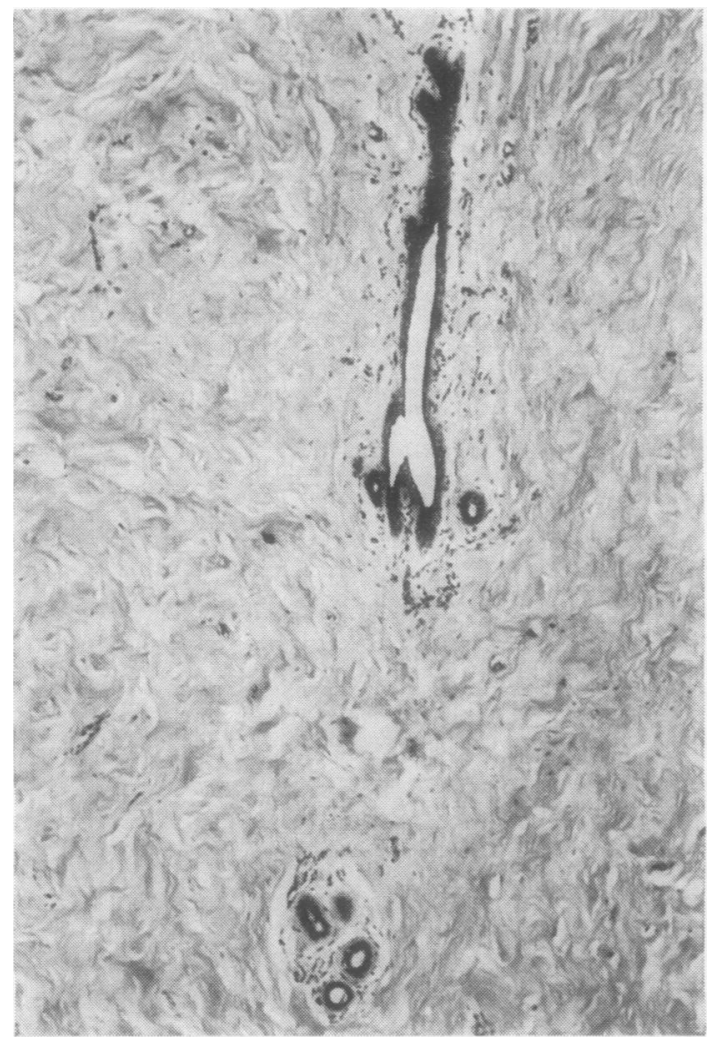

Fig. 1 Duct and ductules embedded in dense fibrous tissue. Haematoxylin and eosin $\times 50$.

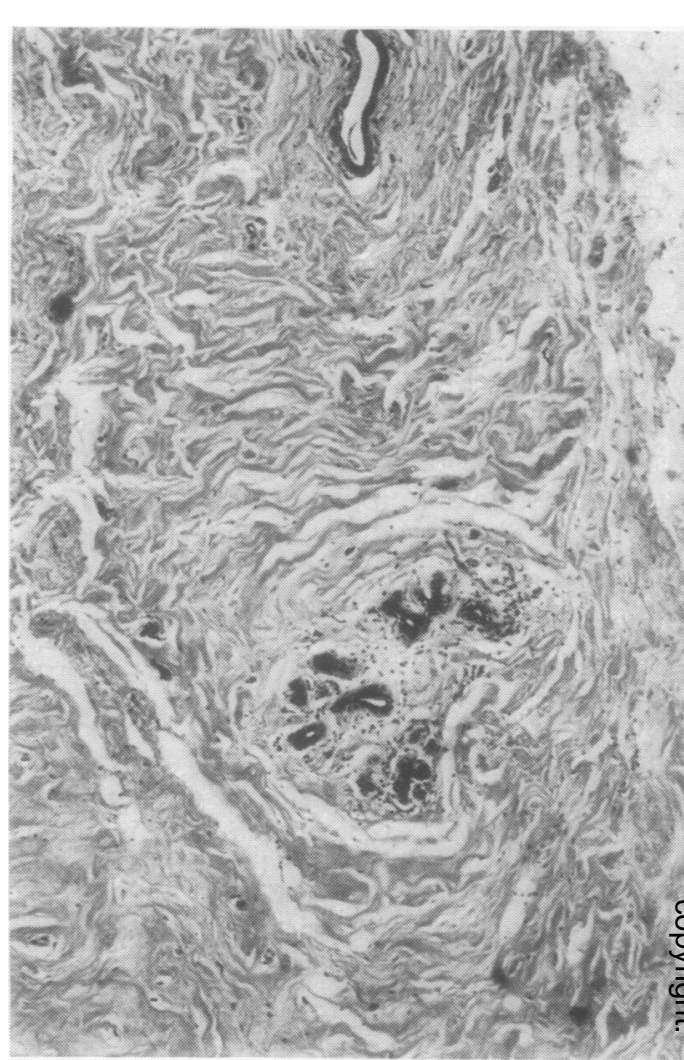

Fig. 2 Ductules amidst dense fibrous tissue showing no evidence of lobular formation. H.\& E. $\times 50$.

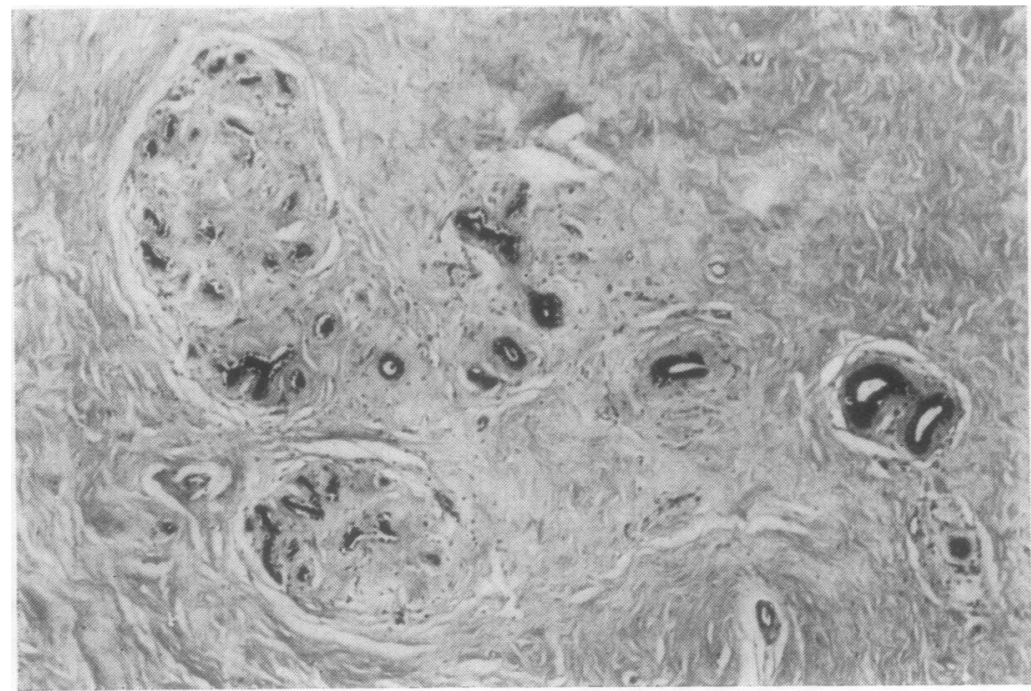

Fig. 3 Abortive lobular formation with dense collagen surrounding solid islands of cells. H. \& E. $\times 50$.

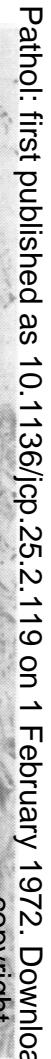

N 


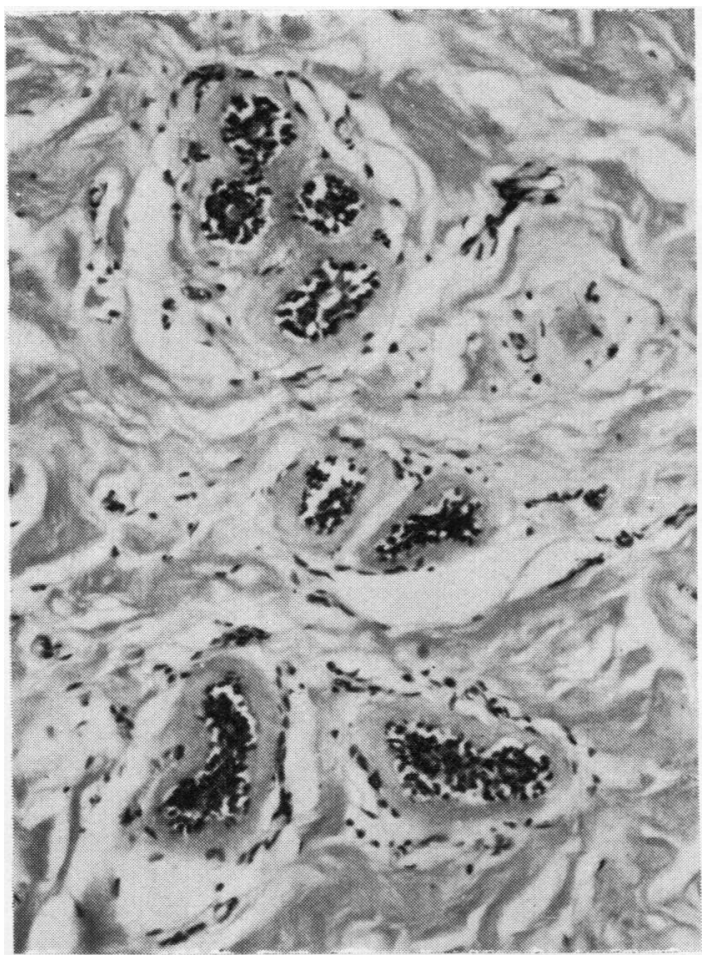

Fig. 4 Detail of abortive lobular formation showing grossly thickened and hyalinized basement membrane. H. \& E. $\times 125$.

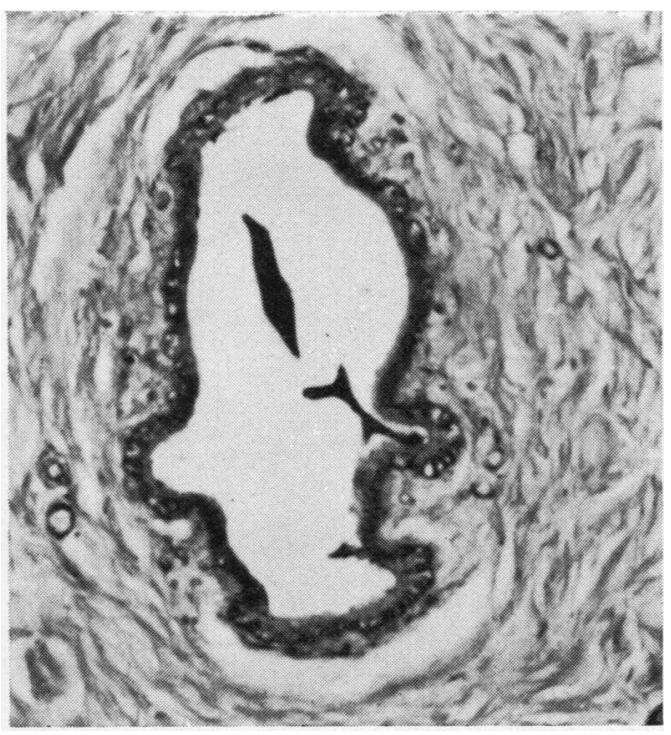

Fig. 5 Ductule showing scant secretion within the lumen. Periodic-acid-Schiff. $\times 125$. tics of amyloid. The larger ducts are invested by a mantle of elastic fibrils amidst the collagen. Periodicacid-Schiff and Alcian green staining show there to be a small amount of secretion within the ductules (Fig. 5) but there is marked reduction in volume. The connective tissue of the breast is seen to be well developed in all sections, and the interlobular collagen bundles have assumed a rather coarse hyaline appearance. There is no evidence of loss of tissue mass or of degenerative changes in the collagen. Despite the long history of bronchiectasis, sections from the liver and kidney showed no evidence of amyloidosis.

\section{Discussion}

Although of approximately normal dimensions, the breast discs show complete lobular agenesis, the appearance of which could be confused initially with that of a quiescent gynaecomastia. The fibrous element of the breast disc is well developed as might be expected from the normal hormonal status, but the glandular element is inhibited. The differences between this appearance and a gynaecomastia lie in the fact that the ductules are not actively budding, and that the ducts are invested by a mantle of elastica and show an intimate relationship to normal myoepithelial cells. Secretion within the ductules is poor, as might be expected from the lack of lobular development, and that which is present appears to be deficient in protein, although some mucin is being elaborated.

Lobular agenesis is not specific for mucoviscidosis, and may occasionally be seen in the normal young adult. It would be reasonable, however, to postulate that the normal hormonal stimulation is responsible for the development of the fibrous element of the breast disc, the nipples and areolae, whilst the genetic defect in the epithelium has modified its response and has inhibited acinar development, so producing the appearance of lobular agenesis.

Although not previously described, the changes within the breast are in keeping with the general hypothesis concerning the genetic defect in this condition. The appearances are in line with the changes described in other exocrine glandular tissues (di Sant Agnese, 1956) with one marked exception. In the pancreas, biliary tract, and bronchial tree one of the characteristic features is mucus plugging of the ducts, and Freye, Kurtz, Spock, and Capp (1964) describe a surface accumulation of mucus in the small intestine. The structural changes in the glands may be secondary to the mucus plugging, whilst in the breast there seems to be a primary defect in the epithelium in that the lobule has failed to develop in response to normal 
hormonal stimulation. Brusilow (1970) makes the assertion that the female genitalia are normal, and the findings in this case would support that view. Menstruation was well established and at necropsy the ovaries, fallopian tubes, and uterus were normally developed.

\section{References}

Bodian, M. (1952). Fibrocystic disease of the pancreas. Heineman, London.
Brusilow, S. W. (1970). Cystic fibrosis in adults. Ann. Rev. Med., 21, 99-104. Di Sant Agnese, P. A. (1956). Cystic fibrosis of the pancreas. Amer. 을
J. Med., 21, 406-422.

Doggett, R. G., Bentinck, B., and Harrison, G. M. (1971). Structure and ultrastructure of the labial salivary glands in patients with $\stackrel{?}{+}$ cystic fibrosis. J. clin. Path., 24, 270-282.

Freye, H. B., Kurtz, S. M., Spock, A., and Capp, M. P. (1964). Light and electron microscopic examination of the small bowel of children with cystic fibrosis. J. Pediat., 64, 575-579.

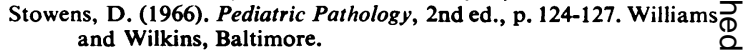

Sweney, L., and Warwick, W. J. (1968). Involvement of the labialo salivary gland in patients with cystic fibrosis. III. Ultra- $心$ structural changes. Arch. Path., 86, 413-418. 